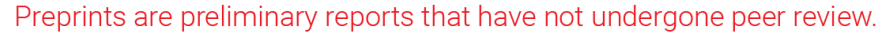 \\ They should not be considered conclusive, used to inform clinical practice, or referenced by the media as validated information. \\ Prenatal and Postnatal Diagnosis and Phenotype of 8p23.2p22 Duplication in One Family
}

\section{Panlai Shi}

Zhengzhou University First Affiliated Hospital

\section{Conghui Wang}

Zhengzhou University First Affiliated Hospital

\section{Yuting Zheng}

Zhengzhou University First Affiliated Hospital

\section{Xiangdong Kong ( $\square$ kongxd@263.net )}

Zhengzhou University First Affiliated Hospital https://orcid.org/0000-0003-0030-7638

\section{Research article}

Keywords: 8p23.1 duplication syndrome, 8p23.2p22 duplication, phenotype, and heterogeneity

Posted Date: September 21st, 2020

DOl: https://doi.org/10.21203/rs.3.rs-52156/v1

License: (9) This work is licensed under a Creative Commons Attribution 4.0 International License. Read Full License

Version of Record: A version of this preprint was published on March 23rd, 2021. See the published version at https://doi.org/10.1186/s12920-021-00940-z. 


\section{Abstract}

Background Distal 8p duplication is rare, but clinically significant.

Methods A family has an induced labor fetal (II-2) for increased nuchal translucency $(3.5 \mathrm{~mm})$ at 12 weeks gestation and detecting a 16.22Mb deletion of 8 p23.2p22 by copy number variation sequencing (CNV-seq). Hence, the family requested family analysis and prenatal diagnosis of subject II-3. All family members underwent CNV-seq, karyotyping and $\mathrm{FISH}$ testing.

Results II-1 and II-3 were found to have a $16.22 \mathrm{Mb}$ duplication of $8 \mathrm{p} 23.2 \mathrm{p} 22$, containing the $8 \mathrm{p} 23.1$ duplication syndrome region, inherited from their father, a carrier with a translocation of 8p22 and 22q13. It's confirmed that duplication site was located on chromosome $22 \mathrm{p} 13$ by combining the results of CNVseq, karyotype and FISH.

II-1 is a 7.5 year old boy. At one month old, he was diagnosed with a ventricular septal defect and treated using surgically at age four. His growth and intelligence developed well, and he performed well in school. His primary issue is an inability to distinguish between the flat tongue and warped tongue in speech. II-3 had a normal ultrasonic index until 26 weeks gestation. The family wants keep the pregnancy, providing us with the opportunity to evaluate the effects of $8 p 23.2 p 22$ duplication in comparison with the brother (II-1).

Conclusion Our study makes a significant contribution to the literature because this relatively rare condition can have significant phenotypical consequences, and an understanding of the inheritance and variability of phenotypes caused by this mutation is essential to an increased understanding of the condition.

\section{Background}

The prevalence of 8p23.1 duplication syndrome has been reported to have an incidence of $1 / 58,000[1]$. The 8p23.1 duplication syndrome has a variable phenotype, with three relatively common manifestations: developmental delay, intellectual disability, and malformation of the heart [1-6]. Other phenotypic effects range from delayed speech and language development and abnormal facial shape to behavioral or psychiatric abnormalities[2, 3, 5-7]. The typical genomic region affected involves $3.68 \mathrm{Mb}$, but a minimal region spanning $776 \mathrm{~kb}$, and containing only eight genes has been suggested by Barber et al $[1,8]$.

The phenotypes vary greatly, from multiple deformities to solely intellectual disabilities. This heterogeneity increased the challenges of evaluating the condition and providing prenatal genetic counseling to families. The Decipher database contains several cases of 8p23.1 duplication. However, there are only three cases $(8: 10001-12655629,12.65 \mathrm{Mb})$ that are close to and smaller than our report (8:160000-16380000, 16.22 Mb). The Decipher IDs are [392337], [395697], and [399307] 
(https://decipher.sanger.ac.uk/). These cases arise from imbalance from a balanced parental rearrangement, maternal inheritance constitutive in the mother, and unknown.

Here, we report a family with a $16.22 \mathrm{Mb}$ duplication of $8 \mathrm{p} 23.2 \mathrm{p} 22$ in both postnatal (II-1) and prenatal members (II-3), with a deletion in the same region in II-2. The chromosomal abnormality of the three members result from their father, a carrier of a balanced translocation of $8 \mathrm{p} 22$ and 22p13.

\section{Methods}

\section{Molecular cytogenetics}

G-banding of chromosomes and fluorescence in situ hybridization (FISH) were carried out using standard techniques. FISH was performed using 8pter (TelVysion 8p Spectrum Green), 8qter (TelVysion 8q Spectrum Orange), and 22qter (TelVysion 22q Spectrum Orange), obtained from the Abbott Laboratories.

\section{Molecular Genetics}

Chorionic villus analysis or amniocentesis was performed according to previously published procedures[9, 10]. DNeasy Blood and tissue kits (Qiagen) were used to extract the genomic DNA of chorionic villus and amniocytes, which was collected by centrifugation and washed with PBS. Quantitative fluorescence PCR (QF-PCR) was used as quality control to detect DNA contamination. Short tandem repeat (STR) markers were used for chromosome 21 (D21S1435, D21S1411, D21S11), chromosome 18 (D18S1002, D18S391, D18S535, D18S386), chromosome 13 (DXS981, DXS6809, DXS22), and the sex chromosomes $X$ and $Y$, according to the previously described procedures.

CNV-seq was performed as previously described[11]. The CNVs identified (blast with hg19) were used to query public databases, including, DGV (http://dgv.tcag.ca/dgv/app/home), gnomAD (https://gnomad.broadinstitute.org/), Decipher (https://decipher.sanger.ac.uk/), OMIM (https://www.omim.org/), UCSC (https://genome.ucsc.edu/) and ClinGen (https://dosage.clinicalgenome.org/). Pathogenicity was assessed according to the latest guidelines outlined by the American College of Medical Genetics (ACMG)[12]. CNVs were classified as five levels: benign, likely benign, variants of uncertain significance (VUS), likely pathogenic, and pathogenic.

\section{Clinical History}

The pregnant women is 35 years old with a history of three pregnancies. Her first child (II-1), a boy, was delivered after a normal pregnancy. At the age of one month, an ultrasound examination revealed that he has a ventricular septal defect (VSD), and he underwent minimally invasive surgery, with a successful outcome, at age four. He is currently 7.5 years old, and has normal intellectual and growth development, with a height of $128 \mathrm{~cm}$ and weight of $28.5 \mathrm{~kg}$. However, a slightly delay of speech and language 
development is apparent, in that he cannot distinguish between the flat tongue and warped tongue. This individual did not undergo genetic diagnosis before II-3 received a prenatal diagnosis. The second fetus (II-2) was found to have increased nuchal translucency $(3.5 \mathrm{~mm})$ at 12 weeks gestation, and was diagnosed prenatally using chorionic villus sampling and CNV-seq testing. The CNV-seq results showed a 16.22 Mb deletion on 8p23.2p22 (seq[hg19] 8p23.2p22 (160000-16380000) x1), which is a pathogenic CNV including 8p23.1 deletion syndrome. The common phenotype of the syndrome is heart abnormality, atrioventricular canal defect, congenital diaphragmatic hernia, cryptorchidism, defects in the atrial septum, hyperactivity, and intellectual disability[13-15]. Therefore, the mother chose to terminate the pregnancy following genetic counseling. In her third pregnancy, although the ultrasound phenotype was normal, she came to our center for prenatal diagnosis and family analysis.

\section{Results}

The pedigree of the family is shown in Fig. 1A. The CNV-seq results showed that II-3 and II-1 have the same duplication s (seq[hg19]8p23.2p22(160000-16380000)x3). Individual II-2 has a deletion of $8 p 23.2 p 22$ (seq[hg19]8p23.2p22(160000-16380000)x1) (Fig. 1B). The results of both parents are normal (data not shown).

- banding analysis showed an addition to chromosome 22 in II-1 and II-3 (46,XN, add(22)), and a suspected balanced translocation of 8p22 and 22p11.2 in the father $(I-1,46, X Y, ? t(8 ; 22)(p 22 ; p 13))$, all of which were confirmed using FISH(Figs. 2 and 3). The karyotype of the mother is normal (data not shown). Discussion

As the father is the carrier of a balanced translocation $(t(8 ; 22)(p 22 ; p 13))$, all three offspring inherited unbalanced chromosome abnormalities: II-2 an 8p23.2p22 deletion, and II-1 and II-3 8p23.2p22 duplications. The $16.22 \mathrm{Mb}$ of $8 \mathrm{p} 23.2 \mathrm{p} 22$ contains 81 protein-coding genes, including a large defensin cluster (23), and a haploinsufficiency gene GATA4. GATA4 is related to atrial septal defect 2, atrioventricular septal defect 4, tetralogy of Fallot, and ventricular septal defect 1, in an autosomal dominant manner [OMIM,600576]. The 8p23.2p22 region contains 8p23.1 deletion syndrome and duplication syndrome. Barber et a/ reported that the prevalence of $8 \mathrm{p} 23.1$ duplication syndrome is $1 / 58,000$, which is the reciprocal of the $8 p 23.1$ deletion syndrome [1] .

The common features of the 8p23.1 deletion syndrome are abnormalities of the heart, atrioventricular canal defect, congenital diaphragmatic hernia, cryptorchidism, defects in the atrial septum, hyperactivity, and intellectual disability [13-15]. In a prenatal case report, Guimiot showed maternal transmission of an interstitial 8p23.1 deletion of about 5.6 Mb to the fetus, which had a normal phenotype according to ultrasound at 20 weeks gestation, while the mother presented with moderate intellectual disability and underwent cardiac surgery for a ventricular septal defect [16]. Faivre reported a fetus with a diaphragmatic hernia at ultrasound, diagnosed with 8p23.1 deletion at 22 weeks gestation[17]. In this study, the second fetus with 8 p23.2p22 deletion, was only found to have increased nuchal translucency 
$(3.5 \mathrm{~mm})$ at 12 weeks of gestation, and labor was later induced. The prenatal phenotype of individuals with a 8 p23.1 deletion, as determined by ultrasound, may vary greatly.

The common features of the 8p23.1 duplication syndrome are abnormal facial shape, behavioral and psychiatric abnormalities, delayed speech and language development, intellectual disability, and malformation of the heart and great vessels $[2,6]$. However, the genetic heterogeneity of $8 p 23.1$ duplication syndrome varies considerably. Barber et a/ reported four probands with $8 p 23.1$ duplications inherited from their normal parent. The size of the 8p23.1 duplication of the probands ranged from $438 \mathrm{~kb}$ to $802 \mathrm{~kb}$, and the main phenotype was delayed development[1]. The minimal region of overlap was $776 \mathrm{~kb}$ from 10,167,881 to 10,943,836. Also, a considerable number of de novo cases are present in the Decipher data base. On cases of single CNVs, seven cases (3.05 Mb to $5.24 \mathrm{Mb}$ ) were selected (Decipher ID [255954],[300950],[322283],[258439],[290136],[262163],[356962]) (https://decipher.sanger.ac.uk/search?q=8\%3A160000-\%2016380000\#consented-patients/results), the phenotype of the first five cases includes abnormalities of cardiovascular system, such as VSD or bicuspid aortic value, the nervous system, including mild global developmental delay, moderate expressive language delay, and intellectual disability, and abnormal facial shape. The other two cases had no clinical phenotype. Glancy and colleagues reported a duplication of 8p23.1p23.2 between $3,539,893$ to $10,323,426$ associated with speech delay, autism and learning difficulties[18].

Here, we reported two cases of $16.22 \mathrm{Mb}$ duplications of 8p23.2p22 in one family. The first child (II-1) of the family is a 7.5 year old boy with normal growth and intellectual development and slightly delayed speech and language development. At the age of one month, ultrasound revealed that he has a VSD, and was followed by successful minimally invasive surgery at age four. He is currently in the first grade of elementary school and performs well. The genotype of II-3 is the same as that of II-1. II-3 did not have any apparent ultrasonic abnormality until 26 weeks of gestation. Due to the heterogeneity of 8p23.1 duplication syndrome and a lack of similar reported cases, it is difficult to evaluate the fetus' further phenotype. However, the mother is strongly motivated to keep the fetus. Following genetic counseling, she still intends to give birth on the expected date, 2020-07-17. This situation provides an excellent opportunity for observation of the growth and development the child after birth.

\section{Conclusion}

We reported a family that having a $16.22 \mathrm{Mb}$ duplication of 8p23.2p22 associated with slightly delayed speech and language development postnatally (II-1), and the same duplication in a prenatal fetus (II-3) with a normal ultrasonic index. The same deletion is present in II-2, all arising from their father, a carrier of a translocation of $8 p 22$ and 22q13. Our study makes a significant contribution to the literature because this relatively rare condition can have significant phenotypical consequences, and an understanding of the inheritance and variability of phenotypes caused by this mutation is essential to an increased understanding of the condition.

\section{Abbreviations}


CNV, copy number variation;

CNV-seq, CNV sequencing

VSD, ventricular septal defect

FISH, fluorescence in situ hybridization

\section{Declarations}

\section{Ethics approval and content to participate}

All subjects provided informed consent for prenatal genetic investigation, and the II-1 is a 7.5-years-old boy, who' consent to participate was obtained from his parents. And the research was approved by the Zhengzhou University Ethics Committee (approval \#KS-2018-KY-36).

\section{Content to publication}

Written informed consent was obtained from the parents of the patient for publication of this article. The parents consent for the publication of their medical data and images.

\section{Availability of data and material}

All data generated or analyzed during this study are included in this published article.

\section{Competing interests}

None declared.

\section{Funding}

This study was supported by National Key R\&D Program of China (grant number: 2018YFC10022062). The fund was mainly used for FISH cost. Dr.Xiangdong Kong is the project leader. The publication cost for this article was funded by corresponding authors.

\section{Authors' contributions}

XK, PS, CW designed the study. YZ performed the experiments and analyzed the data. PS, CW and XK drafted the manuscript and all authors contributed to editorial changes.

\section{Acknowledgements}

We thank the family investigated for their invaluable contribution to this study.

\section{References}


1. Barber JC, Rosenfeld JA, Graham JM, Kramer N, Lachlan KL, Bateman MS, Collinson MN, Stadheim BF, Turner CL, Gauthier JN, et al: Inside the 8p23.1 duplication syndrome; eight microduplications of likely or uncertain clinical significance. Am J Med Genet A 2015, 167A(9):2052-2064.

2. Barber JC, Maloney VK, Huang S, Bunyan DJ, Cresswell L, Kinning E, Benson A, Cheetham T, Wyllie J, Lynch SA, et al. 23.1 duplication syndrome; a novel genomic condition with unexpected complexity revealed by array CGH. Eur J Hum Genet. 2008;8p(1):18-27. ., 16.

3. Barber JC, Bunyan D, Curtis M, Robinson D, Morlot S, Dermitzel A, Liehr T, Alves C, Trindade J, Paramos Al, et al: 8p23.1 duplication syndrome differentiated from copy number variation of the defensin cluster at prenatal diagnosis in four new families. Mol Cytogenet 2010, 3:3.

4. Osoegawa K, Iovannisci DM, Lin B, Parodi C, Schultz K, Shaw GM, Lammer EJ. Identification of novel candidate gene loci and increased sex chromosome aneuploidy among infants with conotruncal heart defects. Am J Med Genet A. 2014;164A(2):397-406.

5. Yu S, Fiedler S, Stegner A, Graf WD. Genomic profile of copy number variants on the short arm of human chromosome 8. Eur J Hum Genet. 2010;18(10):1114-20.

6. Barber JC, Maloney V, Hollox EJ, Stuke-Sontheimer A, du Bois G, Daumiller E, Klein-Vogler U, Dufke A, Armour JA, Liehr T: Duplications and copy number variants of 8p23.1 are cytogenetically indistinguishable but distinct at the molecular level. Eur J Hum Genet 2005, 13(10):1131-1136.

7. Yu S, Zhou XG, Fiedler SD, Brawner SJ, Joyce JM, Liu HY: Cardiac defects are infrequent findings in individuals with 8p23.1 genomic duplications containing GATA4. Circ Cardiovasc Genet 2011, 4(6):620-625.

8. Barber JC, Rosenfeld JA, Foulds N, Laird S, Bateman MS, Thomas NS, Baker S, Maloney VK, Anilkumar A, Smith WE, et al: 8p23.1 duplication syndrome; common, confirmed, and novel features in six further patients. Am J Med Genet A 2013, 161A(3):487-500.

9. Huang L, Jiang T, Liu C. Fetal loss after amniocentesis: analysis of a single center's 7,957 cases in China. Clin Exp Obstet Gynecol. 2015;42(2):184-7.

10. Izetbegovic S, Mehmedbasic S. Early amniocentesis as a method of choice in diagnosing gynecological diseases. Acta Inform Med. 2013;21(4):270-3.

11. Xie C, Tammi MT. CNV-seq, a new method to detect copy number variation using high-throughput sequencing. BMC Bioinformatics. 2009;10:80.

12. Riggs ER, Andersen EF, Cherry AM, Kantarci S, Kearney H, Patel A, Raca G, Ritter DI, South ST, Thorland EC, et al. Technical standards for the interpretation and reporting of constitutional copynumber variants: a joint consensus recommendation of the American College of Medical Genetics and Genomics (ACMG) and the Clinical Genome Resource (ClinGen). Genet Med. 2020;22(2):245-57.

13. Longoni M, Lage K, Russell MK, Loscertales M, Abdul-Rahman OA, Baynam G, Bleyl SB, Brady PD, Breckpot J, Chen CP, et al: Congenital diaphragmatic hernia interval on chromosome 8p23.1 characterized by genetics and protein interaction networks. Am J Med Genet A 2012, 158A(12):3148-3158. 
14. Shimokawa O, Miyake N, Yoshimura T, Sosonkina N, Harada N, Mizuguchi T, Kondoh S, Kishino T, Ohta T, Remco V, et al: Molecular characterization of del(8)(p23.1p23.1) in a case of congenital diaphragmatic hernia. Am J Med Genet A 2005, 136(1):49-51.

15. Devriendt K, Matthijs G, Van Dael R, Gewillig M, Eyskens B, Hjalgrim H, Dolmer B, McGaughran J, Brondum-Nielsen $\mathrm{K}$, Marynen $\mathrm{P}$, et al. Delineation of the critical deletion region for congenital heart defects, on chromosome 8p23.1. Am J Hum Genet. 1999;64(4):1119-26.

16. Guimiot F, Dupont C, Fuentes-Duarte A, Aboura A, Bazin A, Khung-Savatovsky S, Tillous-Borde I, Delezoide AL, Azancot A. Maternal transmission of interstitial 8p23.1 deletion detected during prenatal diagnosis. Am J Med Genet A. 2013;161A(1):208-13.

17. Faivre L, Morichon-Delvallez N, Viot G, Narcy F, Loison S, Mandelbrot L, Aubry MC, Raclin V, Edery P, Munnich A, et al. Prenatal diagnosis of an 8p23.1 deletion in a fetus with a diaphragmatic hernia and review of the literature. Prenat Diagn. 1998;18(10):1055-60.

18. Glancy M, Barnicoat A, Vijeratnam R, de Souza S, Gilmore J, Huang S, Maloney VK, Thomas NS, Bunyan DJ, Jackson A, et al: Transmitted duplication of 8p23.1-8p23.2 associated with speech delay, autism and learning difficulties. Eur J Hum Genet 2009, 17(1):37-43.

\section{Figures}


A

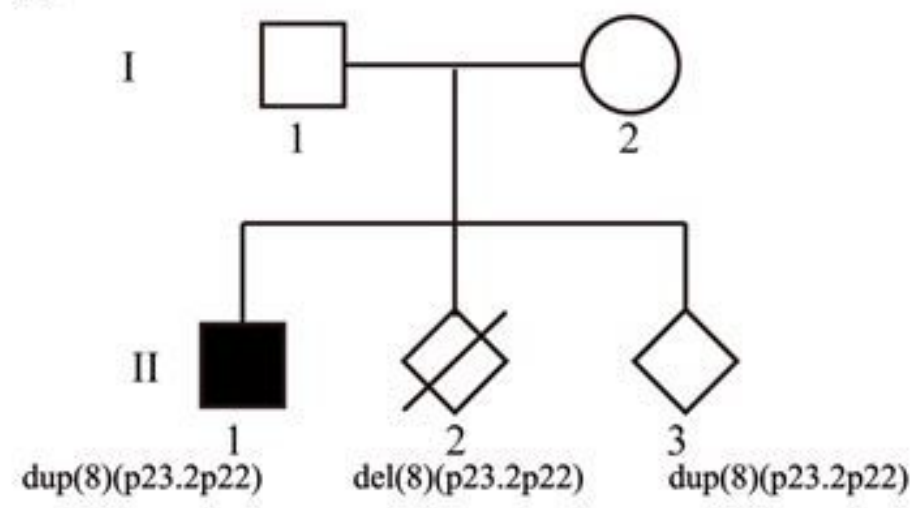

B

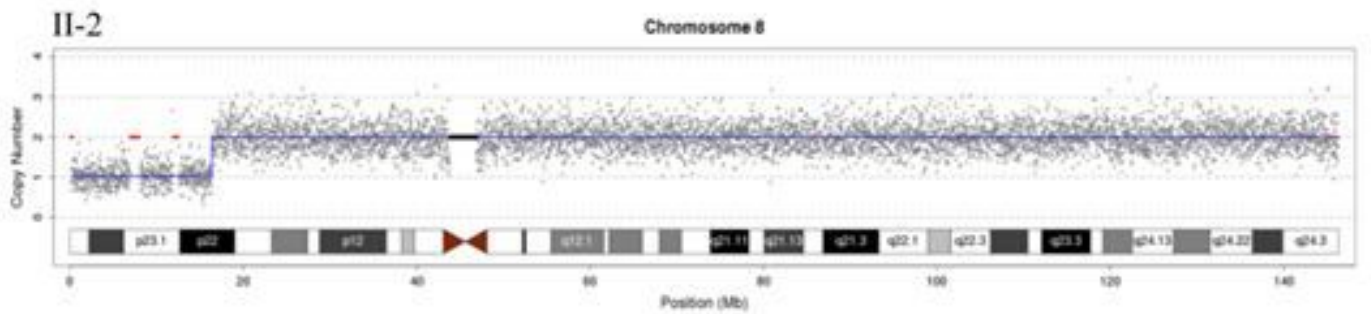

II-1\&II-3

Cavomoseme o

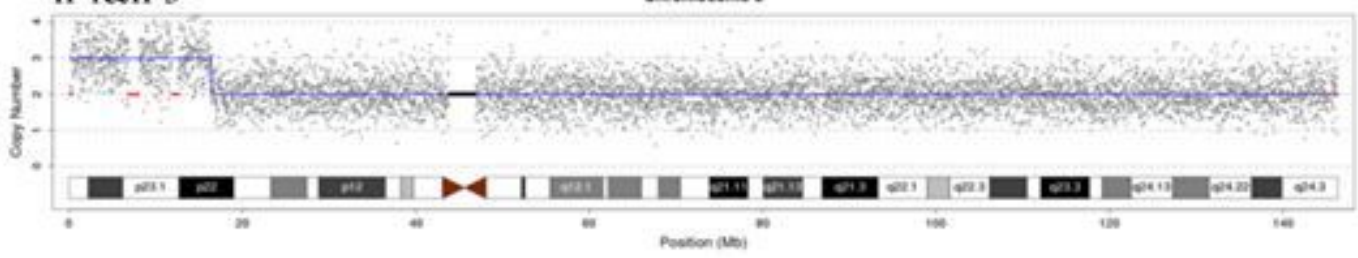

\section{Figure 1}

The pedigree of the family and the CNV-seq results of II-1,II-2, and II-3.The parent results is normal and not showed.

A

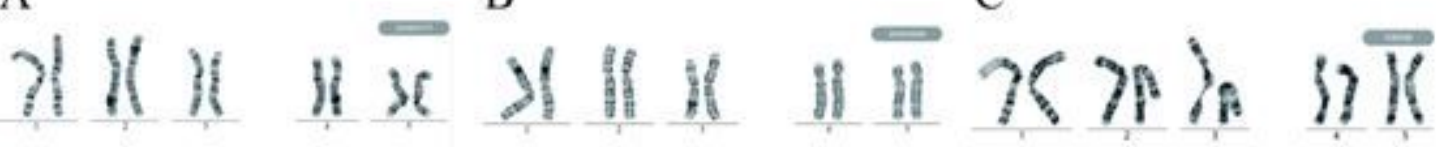

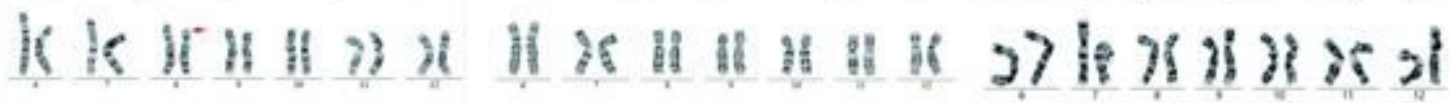

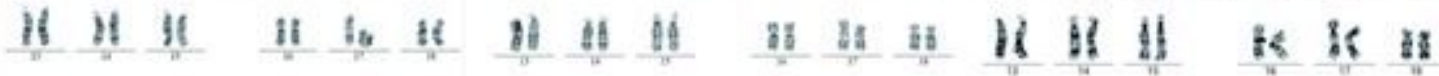

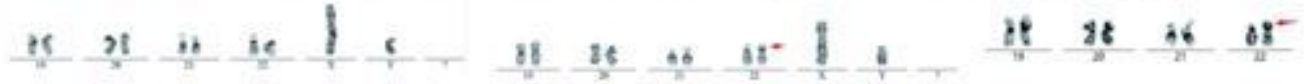
$\mathrm{I}-1$
II-1
II-3

Figure 2

The G-band karyotype of I-1,II-1, and II-3.The mother 'result is normal and not showed, and the II-2 sample is chronic villi and not done the G-band experiment. 
A
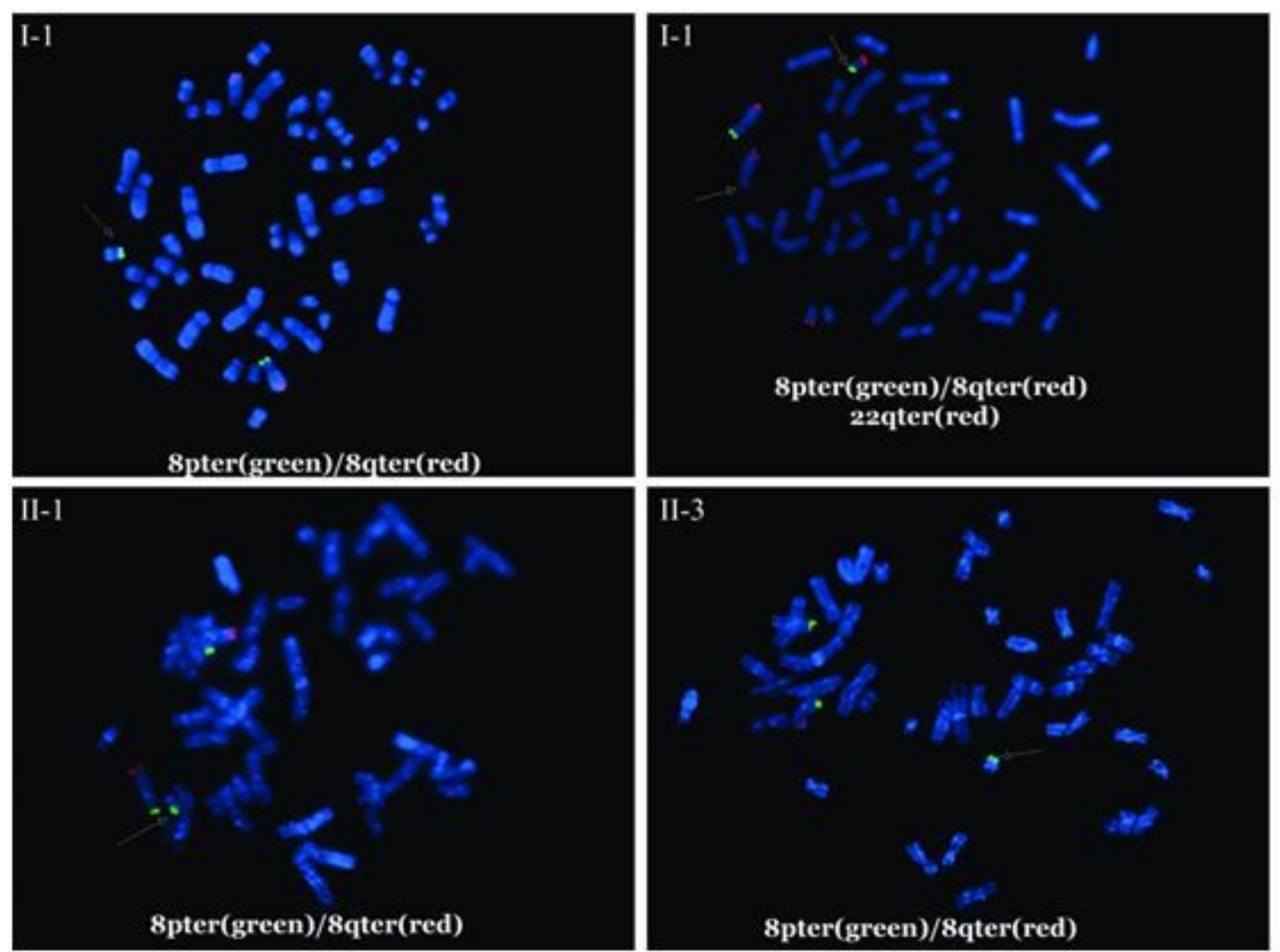

Figure 3

The representive FISH results in I-1, II-1, and II-3. 